Arq. Bras. Med. Vet. Zootec., v.56, n.1, p.94-106, 2004

\title{
Efeitos da seleção individual e da seleção baseada no BLUP em populações diferentes, quanto ao tipo de acasalamento
}

[Individual selection and selection based on BLUP effects in different populations, according to mating design]

\author{
E.E. Cunha ${ }^{1 *}$, R.F. Euclydes ${ }^{2}$, R.A. Torres ${ }^{2}$, P.S. Lopes $^{2}$, J.I. Ribeiro Júnior ${ }^{2}$, P.C.S. Carneiro ${ }^{2}$ \\ ${ }^{1}$ Estudante de Doutorado em Genética e Melhoramento da Universidade Federal de Viçosa \\ Av. P. H. Rolfs, s/n, \\ 36571-000 - Viçosa, MG \\ ${ }^{2}$ Universidade Federal de Viçosa
}

\begin{abstract}
RESUMO
Dados simulados foram utilizados para avaliar o desempenho da seleção individual e da seleção baseada no melhor preditor linear não-viesado (BLUP), em populações que diferiam entre si, quanto ao tipo de acasalamento, no decorrer de 50 gerações. Estudou-se uma característica quantitativa com herdabilidade igual a 0,10 , em populações de 600 indivíduos, que apresentaram a seguinte estrutura: valores de razão sexual (d), de 10 e 50, tamanhos efetivos de população $\left(\mathrm{N}_{\mathrm{e}}\right)$, de 36,36 e 7,84 e intensidade de seleção dos machos $\left(\mathrm{i}_{\mathrm{m}}\right)$, de 2,23 e 2,82. Em cada valor de $d$, formaram-se populações correspondentes ao tipo de acasalamento, em todas as gerações: acasalamentos preferenciais de meios-irmãos e irmãos completos, acasalamentos preferenciais entre meios-irmãos, acasalamentos ao acaso, exclusão de acasalamentos entre irmãos completos e exclusão de acasalamentos de meios-irmãos e irmãos completos. As características avaliadas ao longo das gerações foram: valores fenotípicos médios, consangüinidade média, perda percentual por fixação de alelos desfavoráveis e limite da seleção. Observou-se que o BLUP, o tipo de acasalamento, excluindo acasalamentos entre irmãos e a menor razão sexual, juntos, proporcionaram os melhores resultados de valores fenotípicos, durante 45 gerações de seleção. Nessa estratégia de seleção, verificou-se também atraso no número de gerações necessárias para se atingir determinado nível de consangüinidade.
\end{abstract}

Palavras-chave: simulação, método de seleção, tipo de acasalamento, consangüinidade, tamanho efetivo de população

\begin{abstract}
The performance of individual selection and of selection based on best linear unbiased prediction (BLUP) for simulated data of a low heritability trait $\left(h^{2}=10\right)$ selected for fifty generation in a population of 600 animals with different mating structures were evaluated. The mating structures evaluated were: mating ratio $(d)$ of 10 and 50, population size $\left(N_{e}\right) 36.36$ and 7.84 and male selection intensity $\left(i_{m}\right)$ of 2.23 and 2.82. For each d level half and full sib matings, half sib matings, random mating systems and the exclusion of full sib and of half and full sib matings were also evaluated. The average phenotypic value, average inbreeding, percentage of loss by fixation of undesirable alleles and selection limit were studied. The results suggested that BLUP, mating systems with exclusion of between sib matings, and the smallest mating ratio resulted in higher phenotypic value along the 45 generation of selection and the number of generations to reach a specific inbreeding coefficient considering this selection strategy increased.
\end{abstract}

Keywords: simulation, selection method, mating design, inbreeding, effective population size

Trabalho financiado pelo $\mathrm{CNPq}$

Recebido para publicação em 3 de janeiro de 2003

Recebido para publicação, após modificações, em 29 de setembro de 2003

E-mail: eliz.cunha@bol.com.br 


\section{INTRODUÇÃO}

O problema da consangüinidade tem se tornado relevante nos últimos tempos, devido à maior importância dada à utilização do BLUP, com uso do modelo animal, capaz de otimizar respostas genéticas em curto prazo. De acordo com Bijma e Woolliams (2000), o BLUP é um procedimento utilizado com freqüência em diversas áreas, embora tenha sido desenvolvido no contexto de programas de melhoramento animal. Esses autores relataram seu recente emprego em estudos de melhoramento vegetal e sua introdução no melhoramento de peixes.

Segundo Lynch e Walsh (1998), o uso do BLUP é justificável em situações de grande volume e complexidade de informações de pedigree, uma vez que, ao estimar o valor genético de um indivíduo, ele utiliza todas as informações disponíveis de seus parentes, de forma otimizada, conferindo à seleção, maior acurácia. Cabe enfatizar que a obtenção de melhores respostas no menor intervalo de tempo, utilizando-se de todas as informações disponíveis, conduz geralmente, a aumentos na taxa de consangüinidade, de forma que se torna necessário um balanço entre resposta à seleção, no curto e longo prazos.

A redução da consangüinidade apresenta como vantagens, um melhor uso da variabilidade genética disponível na população-base e uma diminuição na depressão causada pela própria consangüinidade, com relação à característica considerada na seleção. Além disso, pode haver diminuição na depressão para as características adaptativas. Vale a pena ressaltar que essa depressão pode representar no presente, a mais séria restrição ao aumento na consangüinidade, em populações submetidas à seleção (Meuwissen, Woolliams, 1994; Brisbane, Gibson, 1995).

Segundo Sanchez et al. (1999), é possível utilizar melhor a variabilidade genética existente numa população, por meio dos esquemas de seleção atuais e, dessa forma, reduzir a taxa de consangüinidade e seu efeito de depressão, sem prejuízos ao progresso genético.

Toro et al. (1988), simulando vários esquemas de acasalamentos, chamaram a atenção para o fato de que, se as informações de pedigree estiverem disponíveis, por exemplo, para avaliações genéticas, utilizando-se o BLUP, torna-se oportuno utilizá-las, para planejar esquemas de acasalamentos, que reduzam a consangüinidade em populações finitas.

Nesse sentido, inúmeros trabalhos têm sido feitos, associando métodos de seleção e tipos de acasalamento, a fim de otimizar os ganhos genéticos e, principalmente, tentar minimizar os efeitos da endogamia, ao longo das gerações. Ainda nesse contexto, Quinton e Smith (1995) ressaltaram que, em sua maioria, as comparações entre os diferentes métodos de seleção têm sido feitas com o mesmo número de pais selecionados, utilizando-se esquemas de acasalamentos que originem nível baixo e aceitável de consangüinidade. Esses autores sugeriram comparar métodos de seleção no mesmo nível de consangüinidade, a fim de permitir uma seleção mais intensa (poucos machos selecionados), em métodos de menor acurácia.

O objetivo deste estudo foi avaliar o desempenho da seleção individual e da seleção baseada no BLUP, a longo prazo, em populações diferentes, pelos valores da razão sexual e pelo tipo de acasalamento.

\section{MATERIAL E MÉTODOS}

Os dados utilizados foram simulados a partir do programa GENESYS (Euclydes, 1996), desenvolvido para o compilador FORTRAN. Esse sistema trabalha em nível de gene e é capaz de simular genomas suficientemente complexos para avaliar diferentes metodologias de seleção e tipos de acasalamento.

O genoma fundador, a partir do qual se obtiveram todas as populações, tinha 20 pares de cromossomos autossômicos de tamanhos aleatórios, cujo comprimento total era de 4.000 centimorgans e 250 loci quantitativos dialélicos aleatoriamente distribuídos pelos cromossomos. Não tinha cromossomos sexuais, mas tinha efeitos aditivos dos genes simulados, seguindo a distribuição normal. Não apresentava interações do tipo não aditivas entre os genes, apresentando freqüências gênicas iniciais iguais em ambos os 
sexos. Tinha efeitos fixos de sexo e outro efeito com 10 classes. Finalmente, apresentava efeitos de ambiente não controláveis, simulados conforme a distribuição normal e valor médio inicial de 0,50, para as freqüências dos loci quantitativos, simulados, seguindo distribuição uniforme.

Foi simulada apenas uma população-base, correspondente ao valor de herdabilidade $\left(\mathrm{h}^{2}\right)$ de 0,10, sendo constituída de 1.000 indivíduos: 500 machos e 500 fêmeas. Os animais desta população foram obtidos por partenogênese, pois, desde a formação dos gametas até a definição do sexo dos zigotos, todos os processos envolvidos foram inteiramente aleatórios. Então, pôde-se considerar como nulo, o grau de parentesco entre seus indivíduos.

Depois de formada a população-base, simulou-se a população inicial ou população da geração zero, iniciando-se o parentesco entre os indivíduos. Esta população teve origem a partir da seleção e do acasalamento ao acaso entre 10 machos e 100 fêmeas. Os indivíduos dessa população produziram gametas à semelhança do que ocorre numa população real, por meio de um processo denominado por Euclydes (1996) de "caminhada cromossômica", que simula a ocorrência ou não de crossing-over e, portanto, considera as segregações, como sendo mendelianas.
Obtida a população inicial, os animais foram selecionados por meio da seleção individual e da seleção baseada no BLUP, utilizando-se o modelo animal, considerando os efeitos fixos de sexo e daquele com 10 classes, além dos efeitos aleatórios de animal e ambiente no modelo estatístico. A seleção com base no BLUP utilizou as informações de pedigree referentes às três últimas gerações, contidas na matriz de parentesco.

As populações selecionadas tiveram tamanho de 600 indivíduos por geração, correspondendo a seis filhos por casal, tendo a seleção ocorrido ao longo de 50 gerações consecutivas e discretas, com 20 repetições por geração, para reduzir os efeitos da oscilação genética.

O esquema de acasalamentos adotado entre os reprodutores escolhidos para pais da geração seguinte, em cada geração, foi aquele no qual, um reprodutor é acasalado com mais de uma fêmea, assegurando assim a existência de famílias de meios-irmãos.

Utilizando-se desse esquema, estabeleceram-se duas diferentes razões sexuais (d), de 10 e 50, para as quais foram selecionados os respectivos números de machos $\left(\mathrm{N}_{\mathrm{m}}\right)$, de 10 e 2 , por geração. $\mathrm{O}$ número de fêmeas selecionadas $\left(\mathrm{N}_{\mathrm{f}}\right)$, de 100, foi mantido constante em todas as gerações. Essa estrutura encontra-se na Tab. 1.

Tabela 1. Estrutura das populações, em populações de seleções individual e baseada no BLUP

\begin{tabular}{cccccccc}
\hline $\mathrm{D}$ & $\mathbf{N}_{\mathbf{m}}$ & $\mathrm{P}_{\mathrm{m}}$ & $\mathrm{i}_{\mathrm{m}}$ & $\mathrm{N}_{\mathrm{f}}$ & $\mathrm{P}_{\mathrm{f}}$ & $\mathrm{i}_{\mathrm{f}}$ & $\mathbf{N}_{\mathrm{e}}$ \\
\hline 10 & 10 & 0,0333 & 2,227 & 100 & 0,333 & 1,091 & 36,363 \\
50 & 2 & 0,0066 & 2,820 & 100 & 0,333 & 1,091 & 7,843 \\
\hline
\end{tabular}

d- valor de razão sexual; $\mathrm{N}_{\mathrm{m}}$ - número de machos selecionados; $\mathrm{P}_{\mathrm{m}}$ - proporção de machos selecionados; $\mathrm{i}_{\mathrm{m}}$ - intensidade de seleção aplicada aos machos; $\mathrm{N}_{\mathrm{f}}$ - número de fêmeas selecionadas; $\mathrm{P}_{\mathrm{f}}$ proporção de fêmeas selecionadas; $\mathrm{i}_{\mathrm{r}}$ intensidade de seleção aplicada às fêmeas $\mathrm{e} \mathrm{N}_{\mathrm{e}}$ - tamanho efetivo da população.

Calculou-se o $\mathrm{Ne}$ com base na fórmula proposta por Wright (1931), citado por Falconer (1987):

$$
\frac{1}{\mathrm{~N}_{\mathrm{e}}}=\frac{1}{4 \mathrm{~N}_{\mathrm{m}}}+\frac{1}{4 \mathrm{~N}_{\mathrm{f}}}
$$

Em cada valor da razão sexual, formaram-se populações, no total de tipos de acasalamento. Em cada uma delas, estudou-se um tipo de acasalamento efetuado entre os animais selecionados, no decorrer de todas as gerações. Ao todo, foram efetuados cinco diferentes tipos de acasalamento: acasalamentos preferenciais de meios-irmãos e irmãos completos, acasalamentos preferenciais entre meios-irmãos, acasalamentos ao acaso, acasalamentos excluindo irmãos completos e acasalamentos excluindo meiosirmãos e irmãos completos. 
Os parâmetros genéticos utilizados na avaliação do desempenho dos métodos de seleção, em todas as gerações, foram: valores fenotípicos médios, consangüinidade média, perdas em percentagem por fixação de alelos desfavoráveis e limite da seleção.

\section{RESULTADOS E DISCUSSÃO}

Na Fig. 1 (1a, 1b, 1c, 1d e 1e) são apresentados os valores fenotípicos médios das populações, em cada um dos tipos de acasalamento propostos entre os reprodutores selecionados, por meio da seleção individual (SI) e da seleção baseada no BLUP, durante 50 gerações. Os valores para a razão sexual foram de 10 e 50 e os tamanhos efetivos da população, de 36,36 e 7,84, respectivamente.

Foram observados aumentos nos valores fenotípicos médios no decorrer das gerações, em todos os tipos de acasalamento e combinações entre métodos de seleção e razões sexuais, uma vez que por seleção artificial, ao se escolherem os melhores indivíduos para reprodutores, a cada geração, proporciona-se um ganho genético cumulativo.

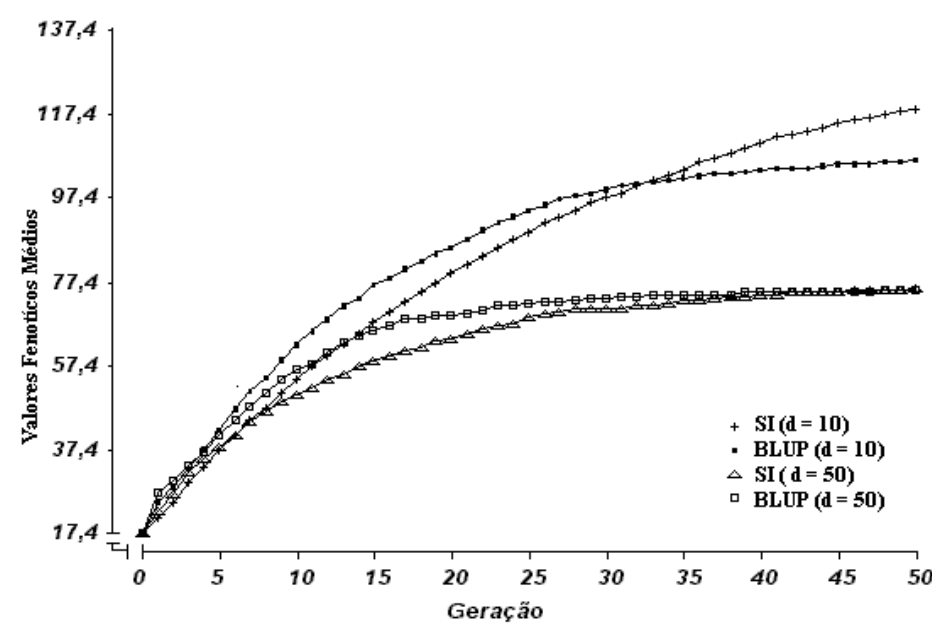

1a. Acasalamento de meios-irmãos e irmãos completos

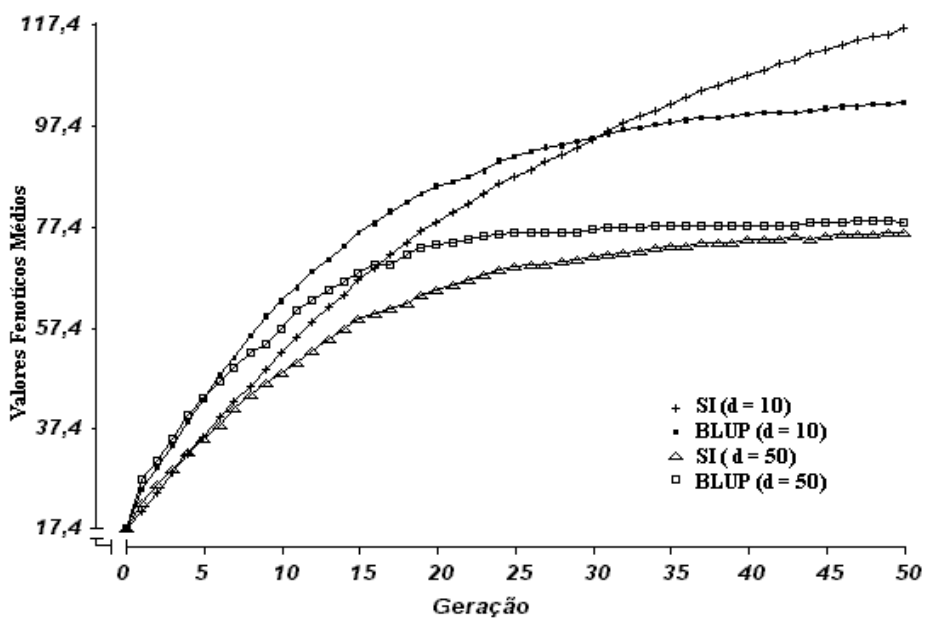

1b. acasalamento entre meios-irmãos 


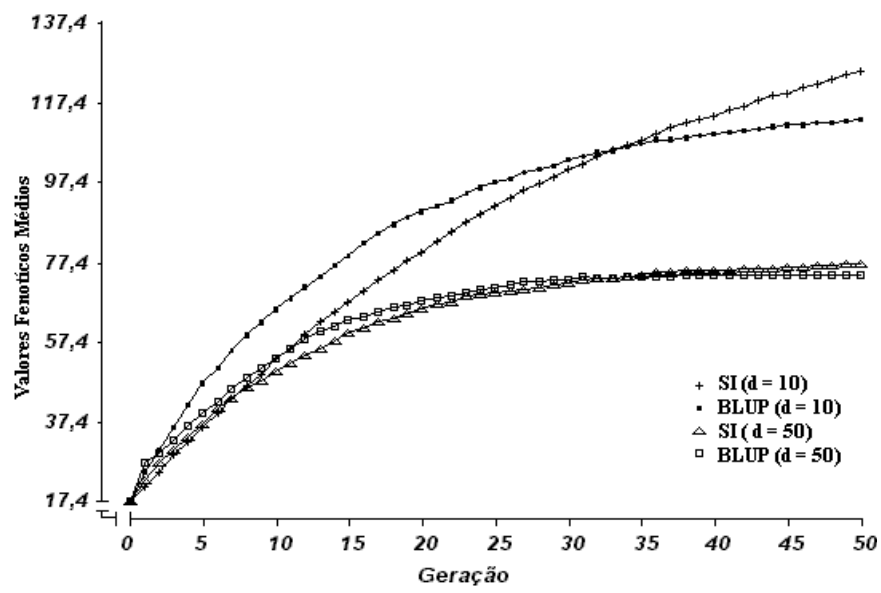

1c. acasalamento ao acaso

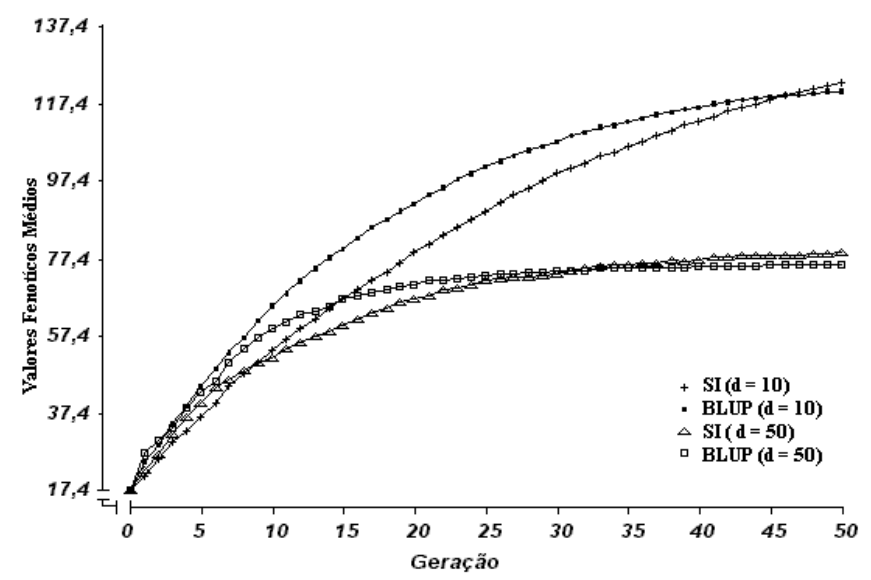

1d. exclusão do acasalamento de irmãos completos

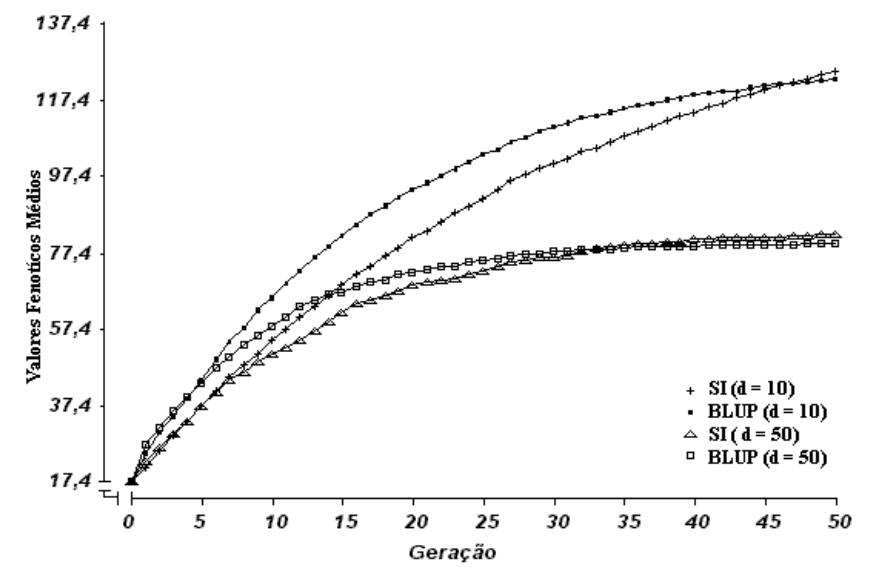

1e. exclusão do acasalamento de meios-irmãos e irmãos completos

Figura 1. Valores fenotípicos médios nos diferentes tipos de acasalamento considerando a seleção individual e a baseada no BLUP, para valores de $\mathrm{d}=10$ e $\mathrm{d}=50$. 
A partir da primeira até, pelo menos, a $10^{\mathrm{a}}$ geração, os maiores valores fenotípicos foram obtidos para o BLUP, independentemente do valor da razão sexual, em todos os tipos de acasalamento. Nesse intervalo, verificou-se, ainda, a superioridade do BLUP em d = 10, com relação ao BLUP em $\mathrm{d}=50$, após as cinco gerações iniciais, em média. Por volta da $15^{\mathrm{a}}$ geração, a SI em d = 10 superou o BLUP em d = 50. Notou-se que desse ponto em diante, houve maior separação entre os valores da razão sexual, tendo sido os maiores valores fenotípicos observados em todas as ocasiões, para $\mathrm{d}=10 \mathrm{e}$ os menores, para $d=50$, considerando-se todos os tipos de acasalamento. Isso era esperado, já que o menor valor da razão sexual $(d=10)$ correspondeu também ao maior tamanho efetivo da população $\left(\mathrm{N}_{\mathrm{e}}=36,36\right)$.

Ressalta-se, ainda, que a seleção baseada no BLUP continuou sendo superior à SI, em cada valor de $d$, pelo menos até 30 gerações após a primeira. A este fato, atribuem-se duas possíveis explicações: primeira, a seleção baseada no BLUP aumenta a acurácia das avaliações genéticas, ao fazer uso de todas as informações disponíveis de parentes dos candidatos à seleção, permitindo otimizar a resposta genética em curto prazo, principalmente para características de baixa herdabilidade, como neste caso; segunda, a seleção individual é mais eficiente em predizer o valor genético do indivíduo para características de média a alta herdabilidade.

Quando se efetuou a comparação entre os tipos de acasalamento, observou-se que os tipos, excluindo acasalamentos entre irmãos (Fig. 1d e 1e), proporcionaram, de modo geral, maiores aumentos nos valores fenotípicos, notavelmente para o BLUP em $\mathrm{d}=10$, no decorrer das gerações. Isto parece estar relacionado com a própria natureza desses acasalamentos, em limitar aumentos na consangüinidade dos descendentes.

Os valores de consangüinidade média encontram-se na Fig. 2 (2a, 2b, 2c, 2d e 2e) e se referem às populações submetidas a cada um dos tipos de acasalamento estudados com relação ao valor fenotípico, naquela mesma seqüência, durante as 50 gerações de seleção individual e de seleção baseada no BLUP, nos valores de $d=10$ e $\mathrm{d}=50$.
Observaram-se aumentos nos valores da consangüinidade, ao longo das gerações, em todos os tipos de acasalamento e combinações entre métodos de seleção e razões sexuais. As taxas de aumento foram maiores nos tipos de acasalamento, com preferência para os acasalamentos entre irmãos (Fig. 2a e 2b), nos quais, de modo geral, foram observados os maiores valores de consangüinidade média, ao longo das gerações. Isso já era esperado, pois esses acasalamentos foram restritos a indivíduos que apresentavam elevado grau de parentesco entre si, aumentando, conseqüentemente, o coeficiente de consangüinidade de suas progênies. Os tipos que melhor controlaram os aumentos na taxa de consangüinidade, em curto e médio prazos, foram os que excluíram acasalamentos entre irmãos (Fig. 2d e 2e), nos quais, as populações exibiram os maiores valores fenotípicos (Fig. 1d e 1e), após 10 gerações, em média. Foi observado que, nesses tipos de acasalamento, o controle da consangüinidade foi mais efetivo no menor valor da razão sexual $(d=$ 10) e teve maior efeito sobre os resultados de valores fenotípicos obtidos com o BLUP, que permaneceu superior à SI por maior número de gerações.

Quanto aos métodos de seleção, constatou-se para o BLUP, maior valor de consangüinidade, durante todas as gerações, em cada valor de $d$, embora ele tivesse proporcionado, desde o início, melhores resultados fenotípicos. Tal fato fez com que, no decorrer das gerações, o ganho genético obtido pelo uso do BLUP fosse superado pelo ganho da seleção individual. Outros autores, como Kuhlers e Kennedy (1992), Quinton e Smith (1995) e Euclydes (1996), já haviam verificado isso.

No menor valor de razão sexual $(\mathrm{d}=10)$, as diferenças de consangüinidade entre os métodos de seleção foram muito mais acentuadas do que na maior razão $(d=50)$, ao longo das gerações, tendência essa observada anteriormente quanto aos valores fenotípicos médios. Isso se deve ao fato de a maior razão sexual $(\mathrm{d}=50)$ expressar, por si própria, maior taxa de consangüinidade, uma vez que ela representa a maior intensidade de seleção aplicada aos machos e, ainda, o menor tamanho efetivo da população. Dessa forma, seu efeito teria sido mais importante do que o dos métodos de seleção e tipos de acasalamento, na 
determinação dos níveis de consangüinidade nas populações.

Verificou-se, de modo geral, que independentemente do tipo de acasalamento praticado, a partir da geração de número 25 , a consangüinidade média já tinha ultrapassado $50 \%$, tendo sido observados valores de consangüinidade muito altos, de quase $100 \%$ ao final das 50 gerações, valores esses inconsistentes em populações animais. É interessante perceber, contudo, que ao se fixar um valor arbitrário para o nível de consangüinidade, os tipos de acasalamento diferiram entre si quanto ao número de gerações necessárias para atingir esse mesmo valor, com atrasos significativos verificados nos tipos que excluíram acasalamentos entre irmãos (Fig. 2d e 2e), principalmente no menor valor da razão sexual $(d=10)$.

Na Fig. 3 (3a, 3b, 3c, 3d e 3e) estão os valores, em percentagem, de perdas por fixação de alelos desfavoráveis, referentes à mesma seqüência de tipos de acasalamento avaliada nos estudos anteriores. Observou-se, de modo geral, que houve aumentos nas taxas percentuais de perdas, no decorrer das gerações, em todos os tipos de acasalamento e combinações, que foram maiores nos tipos de acasalamento, com preferência para os acasalamentos entre irmãos (Fig. 3a e 3b), bem como no maior valor da razão sexual $(\mathrm{d}=$ 50). Verificou-se que, da primeira até a quinta geração, o BLUP provocou as maiores perdas, independentemente do valor de $d$, em todos os tipos de acasalamento. A partir da $10^{\mathrm{a}}$ geração, os maiores valores de perdas por fixação, em ordem decrescente, foram observados para BLUP em $d=50$, SI em $d=50$, BLUP em $d=$ 10 e SI em $d=10$. Essa mesma seqüência foi observada antes, com relação à consangüinidade média (Fig. 2), revelando que a SI proporcionou menores perdas por fixação.

Os valores do limite da seleção, também referentes à mesma seqüência de tipos de acasalamento e situações avaliadas, podem ser vistos na Fig. 4 (4a, 4b, 4c, 4d e 4e). Foram observados decréscimos nos valores do limite, em todos os tipos de acasalamento e possíveis combinações entre métodos de seleção e razões sexuais. De modo resumido, as maiores taxas de decréscimo foram, em ordem decrescente, obtidas nas combinações BLUP em $\mathrm{d}=50$, SI em $d=50$, BLUP em $d=10$ e SI em $d=10$, que corresponderam à seqüência já observada com relação à consangüinidade média (Fig. 2) e às perdas por fixação (Fig. 3), porém em sentido de acréscimo.

De maneira geral, nos tipos de acasalamento, excluindo aqueles entre irmãos (Fig. 4d e 4e), foram observadas menores taxas de decréscimo nos valores do limite, em todas as combinações, principalmente para o BLUP em $\mathrm{d}=10$. Isso faz sentido, uma vez que nesses tipos de acasalamento, encontraram-se menores valores de consangüinidade média (Fig. $2 d$ e 2 e) e também, menores perdas por fixação (Fig. $3 \mathrm{~d}$ e $3 \mathrm{e}$ ). O tipo de acasalamento ao acaso apresentouse intermediário em relação aos tipos de acasalamento, com preferência entre irmãos, e aqueles que excluíram acasalamentos de irmãos. Assim, em relação aos valores fenotípicos (Fig. $1)$, no maior valor de $d(\mathrm{~d}=50)$, o acasalamento ao acaso (Fig. 1c) proporcionou resultados similares aos tipos que excluíram acasalamentos de irmãos (Fig. 1d e 1e). No menor valor de $d$ (d $=10$ ), este tipo foi mais parecido com aqueles com preferência para acasalamentos entre irmãos (Fig. 1a e 1b), principalmente com o uso do BLUP, apesar de controlar mais eficientemente os aumentos na consangüinidade média (Fig. 2c), as taxas de perdas por fixação (Fig. 3c) e os decréscimos no limite da seleção (Fig. 4c).

\section{CONCLUSÕES}

Os tipos de acasalamento, excluindo acasalamentos entre irmãos, não permitiram o controle sobre os níveis de consangüinidade no maior valor da razão sexual. Essa estratégia, no menor valor da razão sexual, apenas atrasou o número de gerações necessárias para atingir determinado nível de consangüinidade, sem, contudo, impedir seu aumento. Verificou-se, que mesmo para característica de baixa herdabilidade, $\mathrm{h}^{2}=0,10$, a seleção individual superou aquela baseada no BLUP, pelo menos após as 30 primeiras gerações, nos diferentes tipos de acasalamento e valores da razão sexual. 


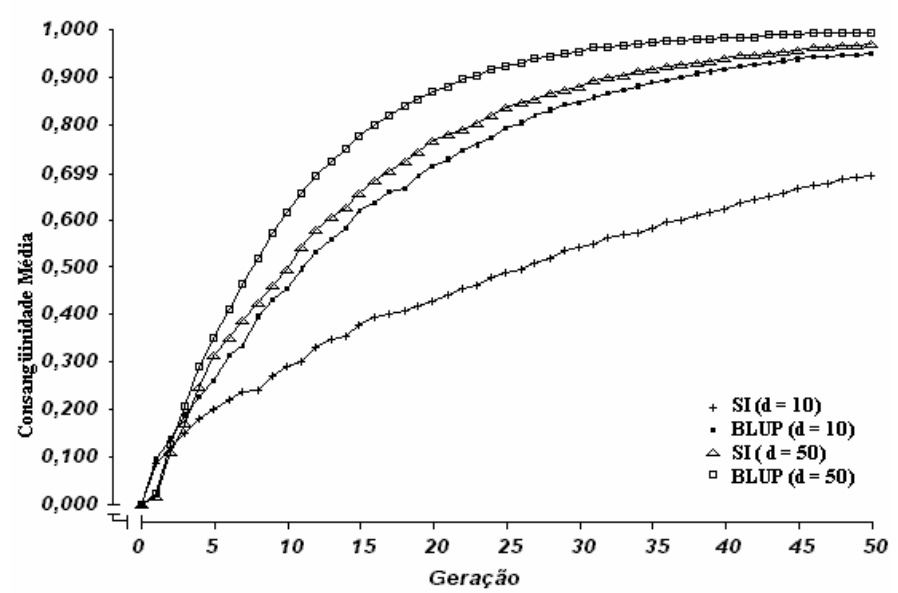

2a. Acasalamento de meios-irmãos e irmãos completos

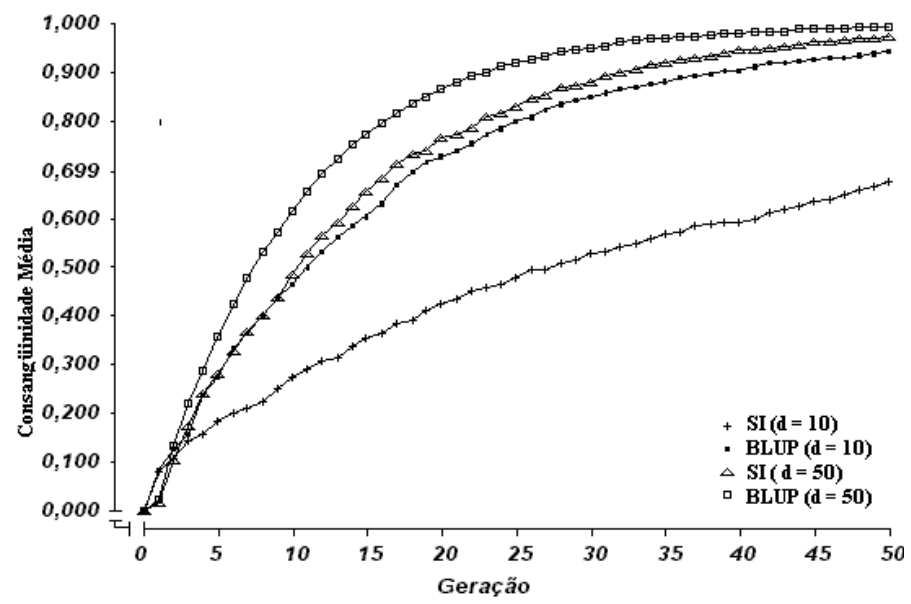

2b. acasalamento entre meios-irmãos

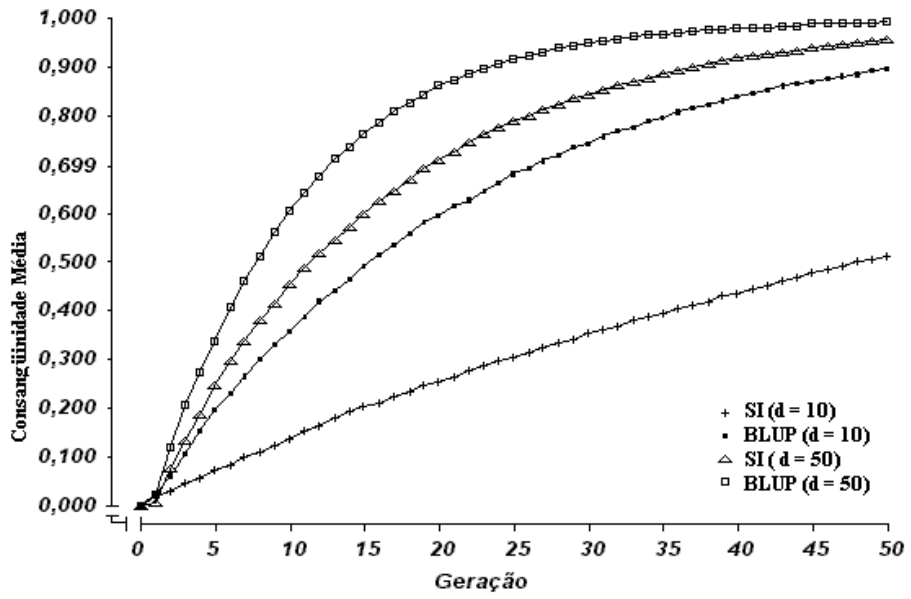

2c. acasalamento ao acaso 


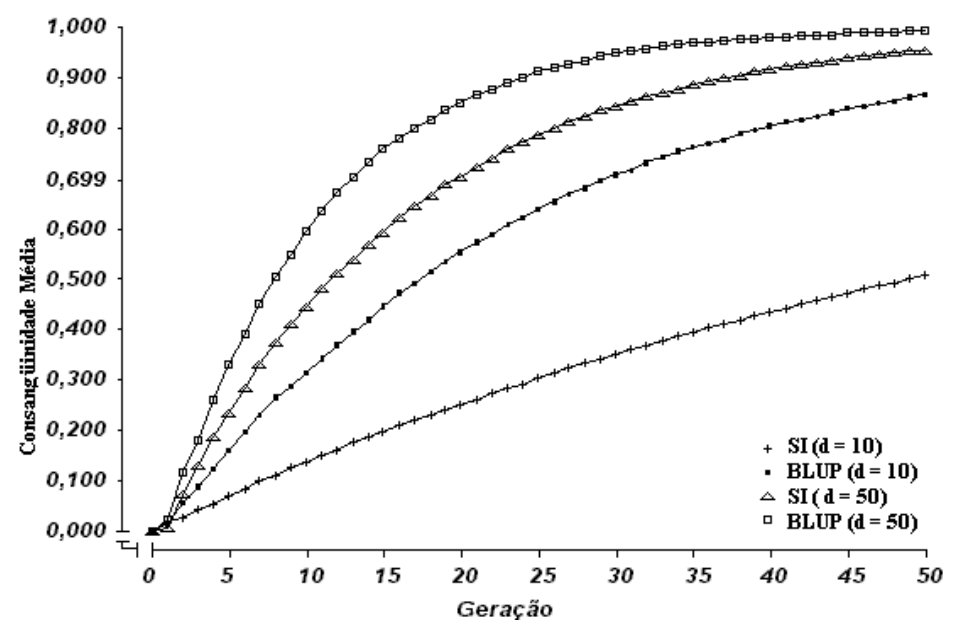

2d. exclusão do acasalamento de irmãos completos

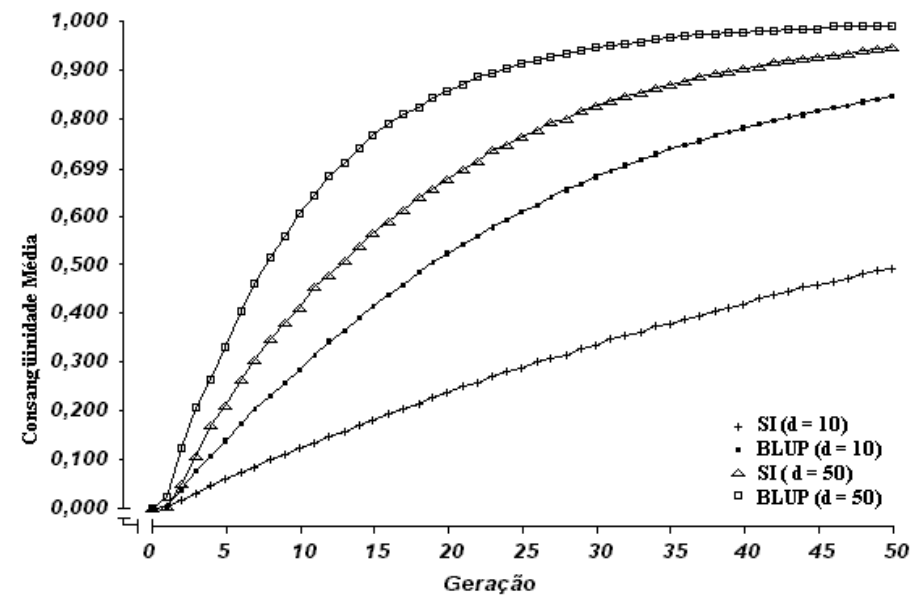

2e. exclusão do acasalamento de meios-irmãos e irmãos completos

Figura 2. Valores de consangüinidade média nos diferentes tipos de acasalamento considerando a seleção individual e a baseada no BLUP, para valores de $\mathrm{d}=10$ e $\mathrm{d}=50$.

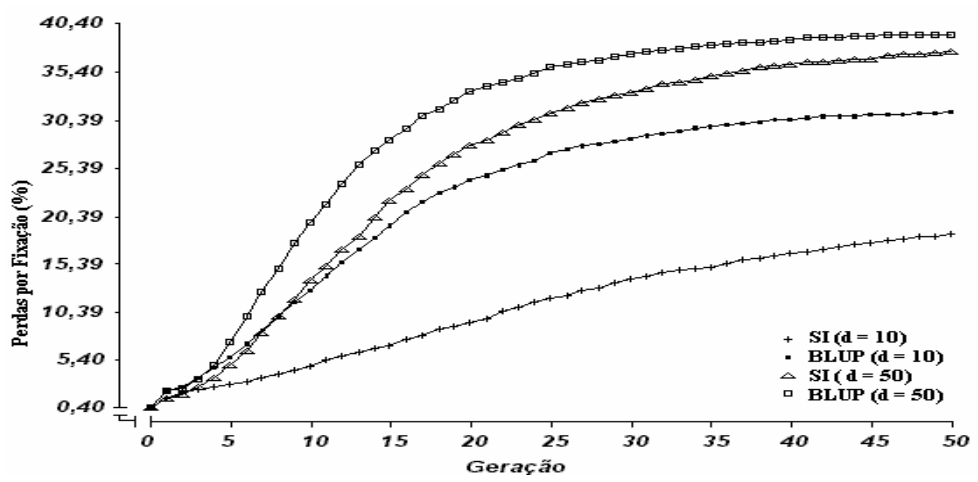

3a. Acasalamento de meios-irmãos e irmãos completos 
Efeitos da seleção individual e da seleção baseada no BLUP...

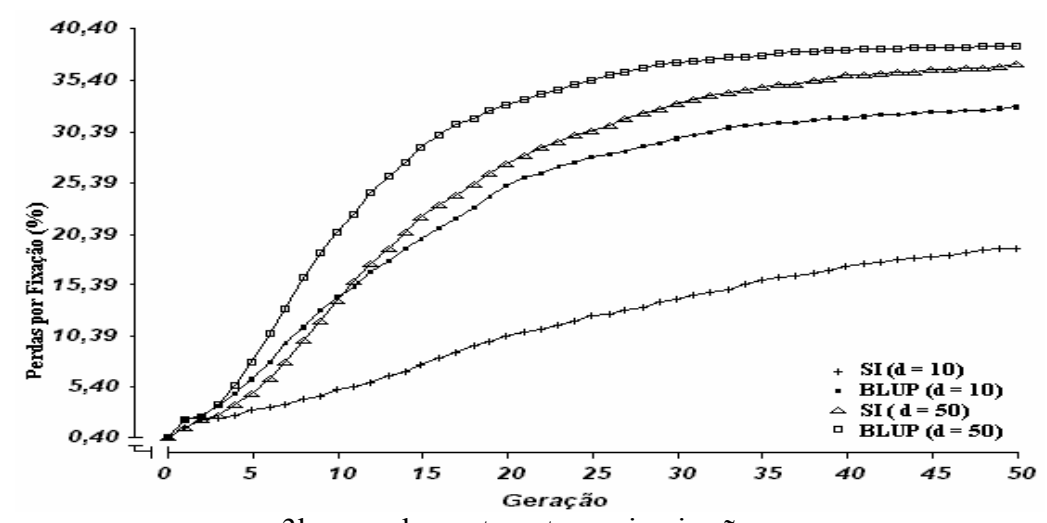

3b. acasalamento entre meios-irmãos

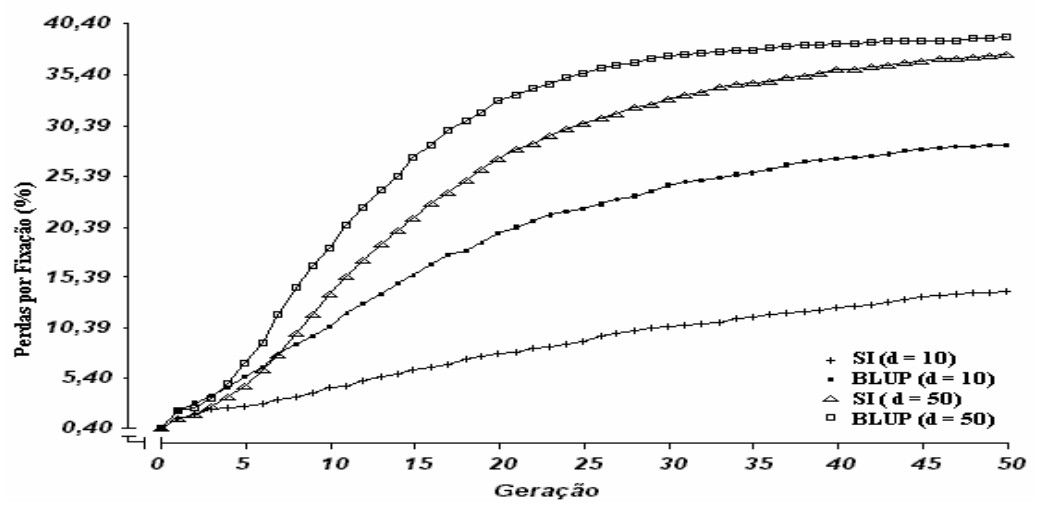

3c. acasalamento ao acaso

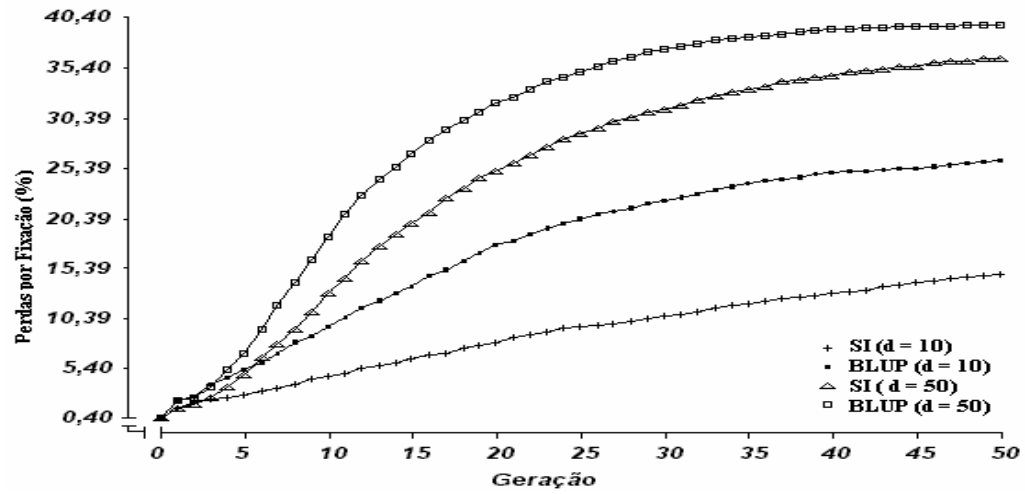

3d. exclusão de acasalamento de irmãos completos 


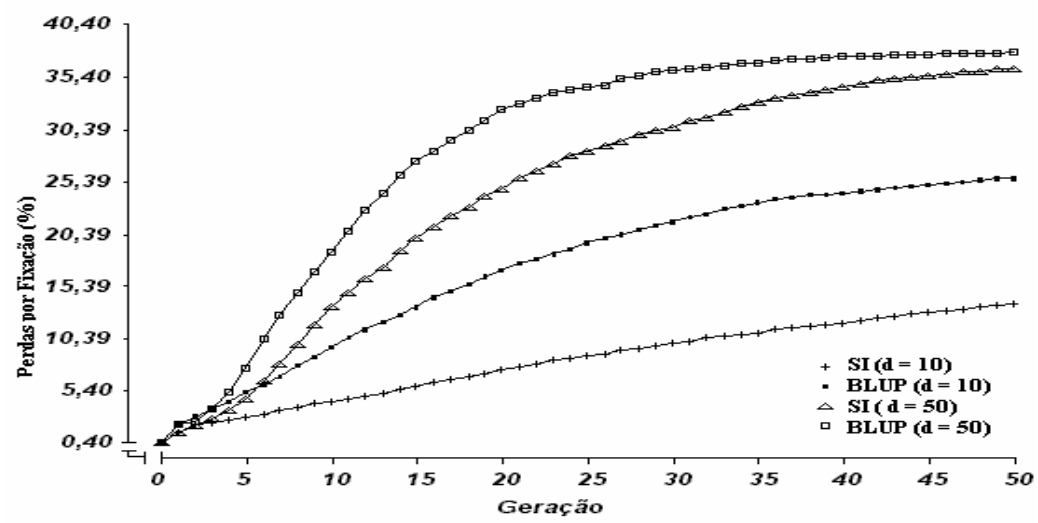

3e. exclusão do acasalamento de meios-irmãos e irmãos completos

Figura 3. Valores de perdas por fixação de alelos desfavoráveis nos diferentes tipos de acasalamento considerando a seleção individual a baseada no BLUP, para valores de $d=10$ e $d=50$.

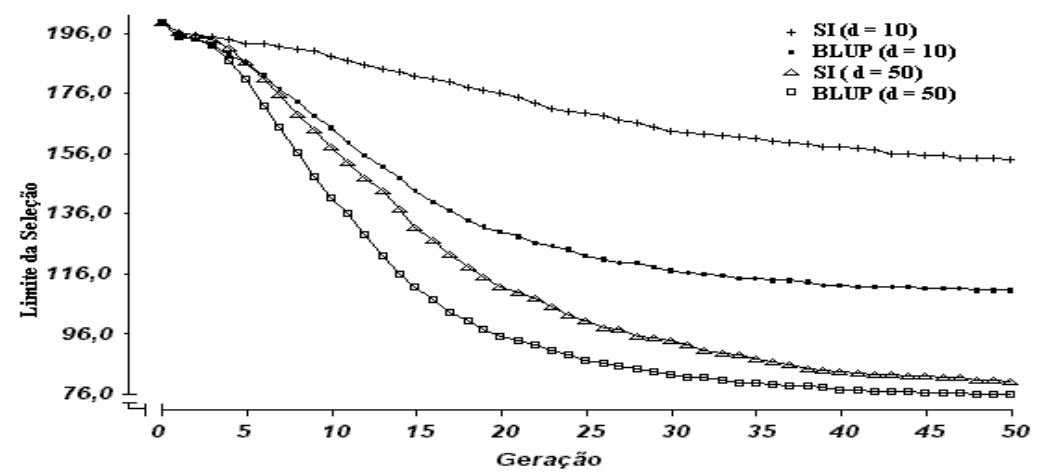

4a. acasalamento de meios-irmãos e irmãos completos

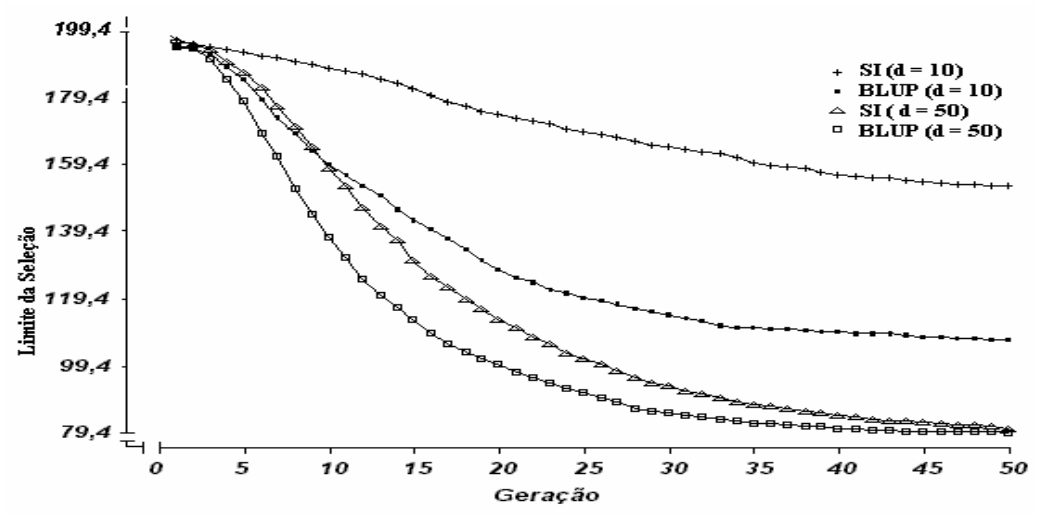

4b. acasalamento entre meios-irmãos 


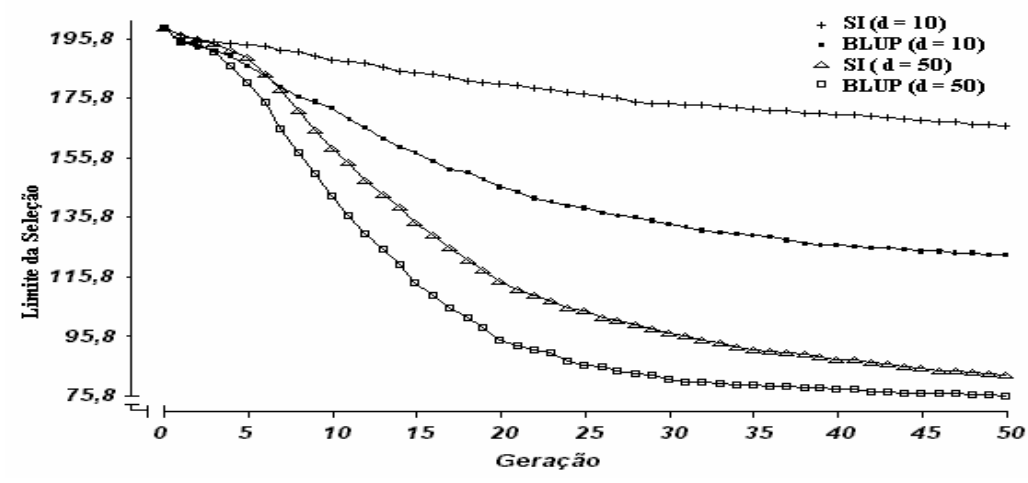

4c. acasalamento ao acaso

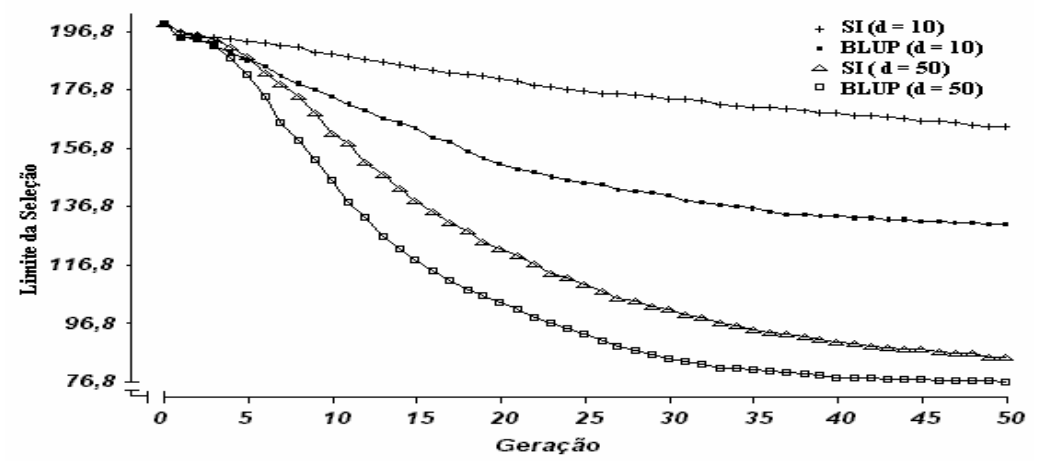

4d. exclusão do acasalamento de irmãos completos

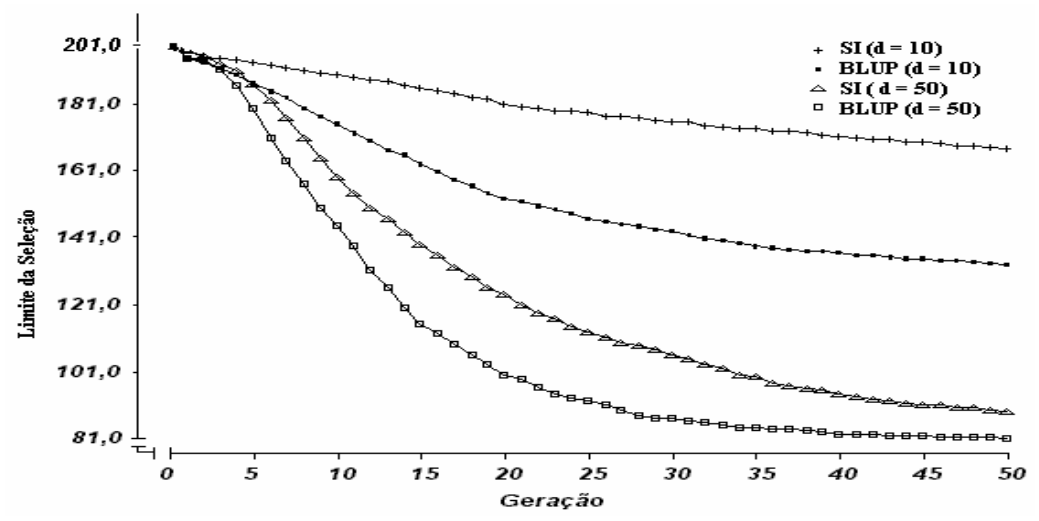

4e. exclusão do acasalamento de meios-irmãos e irmãos completos

Figura 4. Valores do limite da seleção nos diferentes tipos de acasalamento considerando a seleção individual e a baseada no BLUP, para valores de $d=10$ e $d=50$.

\section{REFERÊNCIAS BIBLIOGRÁFICAS}

BIJMA, P.; WOOLLIAMS, J. A. Prediction of rates of inbreeding in populations selected on best linear unbiased prediction of breeding value. Genetics, v. 156, p. 361-373, 2000.

BRISBANE, J. R.; GIBSON, J. P. Balancing selection response and rate of inbreeding by including genetic relationships in selection 
decisions. Theor. Appl. Genet., v. 91, p. 421-431, 1995.

EUCLYDES, R. F. Uso do sistema para simulação Genesys na avaliação de métodos de seleção clássicos e associados a marcadores moleculares. 1996. 149f. Tese (Doutorado em Genética e Melhoramento) - Universidade Federal de Viçosa, Viçosa, MG

FALCONER, D. S. Introdução à genética quantitativa. $2^{\mathrm{a}}$ impressão. Viçosa, MG: UFV, 1987. 279p.

KUHLERS, D. L.; KENNEDY, B. W. Effect of culling on selection response using a phenotypic selection or best linear unbiased prediction of breeding values in small closed herds of swine. $J$. Anim. Sci., v. 70, p. 2338-2348, 1992.

LYNCH, M.; WALSH, B. Genetics and analyses of quantitative traits. Sunderland: Sinauer Associates, 1998.

MEUWISSEN, T. H. E.; WOOLLIAMS, J. A. Effective sizes of livestock populations to prevent a decline in fitness. Theor. Appl. Genet., v. 89, p. 1019-1026, 1994.

QUINTON, M.; SMITH, C. Comparison of evaluation-selection systems for maximizing genetic response at the same level of inbreeding. J. Anim. Sci., v. 73, p. 2208-2212, 1995.

SANCHEZ, L.; TORO, M. A.; GARCIA, C. Improving the efficiency of artificial selection: more selection pressure with less inbreeding. Genetics, v.151, p. 1103-1114, 1999.

TORO, M. A.; NIETO, B.; SALGADO, C. A note on minimization of inbreeding in smallscale selection programmes. Livest. Prod. Sci., v. 20, p. 317-323, 1988. 